\title{
Structural and Energetic Basis of Isopropylmalate Dehydrogenase Enzyme Catalysis
}

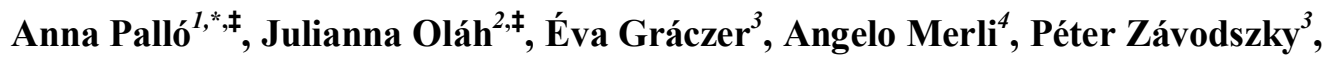 \\ Manfred S. Weiss ${ }^{5}$ and Mária Vas ${ }^{3}$
}

${ }^{1}$ Institute of Organic Chemistry, Research Centre of Natural Sciences, Hungarian Academy of Sciences, Magyar tudósok krt. 2., H-1117 Budapest, Hungary

${ }^{2}$ Department of Inorganic and Analytical Chemistry, Budapest University of Technology and Economics, Gellért Square 4., H-1111 Budapest, Hungary

${ }^{3}$ Institute of Enzymology, Research Centre of Natural Sciences, Hungarian Academy of Sciences, Magyar tudósok krt. 2., H-1117 Budapest, Hungary

${ }^{4}$ Universitá degli Studi di Parma, Dipartimento di Bioscienze, Viale G.P. Usberti 23/A, I-43100 Parma, Italy.

${ }^{5}$ Helmholtz-Zentrum Berlin für Materialien und Energie, Macromolecular Crystallography (HZBMX), Albert-Einstein-Str. 15, D-12489 Berlin, Germany

*Current address: Structural Biology Research Center, VIB, 1050 Brussels, Belgium; Brussels Center for Redox Biology, 1050 Brussels, Belgium; Structural Biology Brussels Laboratory, Vrije Universiteit Brussel, 1050, Brussels, Belgium

${ }^{\ddagger}$ These authors contributed equally to the present work.

To whom correspondence should be addressed:

Manfred S. Weiss, Helmholtz-Zentrum Berlin für Materialien und Energie, Macromolecular Crystallography (HZB-MX), Albert-Einstein-Str. 15, D-12489 Berlin, Germany, E-mail: manfred.weiss@helmholtz-berlin.de

Mária Vas, Institute of Enzymology, Research Centre of Natural Sciences, Hungarian Academy of Sciences, Magyar tudósok krt. 2., H-1117 Budapest, Hungary, E-mail: vas.maria@ttk.mta.hu

Running title: Active Site Structure of 3-Isopropylmalate Dehydrogenase

Enzymes: 3-Isopropylmalate Dehydrogenase [EC 1.1.1.85]

Isocitrate Dehydrogenase [EC 1.1.1.42]

Tartrate Dehydrogenase [EC 1.1.1.93]

Malate Dehydrogenase (decarboxylating) [EC 1.1.1.39]

Database: structural data are available in the Protein Data Bank under the accession number 4F7I.

Keywords: isopropylmalate dehydrogenase, oxidative decarboxylation, general base catalysis, X-ray crystallography, QM/MM calculations 


\begin{abstract}
The three-dimensional structure of the enzyme 3-isopropylmalate dehydrogenase from the bacterium Thermus thermophilus in complex with $\mathrm{Mn}^{2+}$, its substrate isopropylmalate and its cofactor product NADH at $2.0 \AA$ resolution features a fully closed conformation of the enzyme. Upon closure of the two domains the substrate and the co-factor are brought into precise relative orientation and close proximity with the distance between the $\mathrm{C} 2$-atom of the substrate and the $\mathrm{C} 4 \mathrm{~N}$-atom of the pyridine ring of the co-factor of about $3.0 \AA$. The structure further identifies binding of a $\mathrm{K}^{+}$-ion close to the active site and provides an explanation for its known activating effect. Hence, this structure is an excellent mimic for the enzymatically competent complex. Using high-level QM/MM calculations it can be demonstrated that in the observed arrangement of the reactants the transfer of a hydride from the C2-atom of IPM to the C4N-atom of the pyridine ring of $\mathrm{NAD}^{+}$is easily possible with an activation energy $\Delta \mathrm{E}^{*}$ of about $15 \mathrm{kcal} / \mathrm{mol}$ that is turned out to be about 4-6 kcal $/ \mathrm{mol}$ higher upon omission of $\mathrm{K}^{+}$-ion. In the most plausible scenario, the $\varepsilon$-amino-group of Lys185 acts as a general base in the reaction aiding the deprotonation reaction prior to the hydride transfer by providing a low-barrier proton-shuttle mechanism via a water molecule.
\end{abstract}




\section{INTRODUCTION}

Oxidative decarboxylation is an important oxidative process in biology. It is, for instance, employed in the ubiquitous citric acid cycle and in amino acid metabolism. Due to the loss of carbon dioxide in the course of the reaction, the reaction is essentially unidirectional. The oxidant is typically a pyridine nucleotide such as $\mathrm{NAD}^{+}$. One of the enzymes catalyzing such a reaction is 3-isopropylmalate dehydrogenase, IPMDH [EC 1.1.1.85], a member of the $\beta$-hydroxyacid oxidative decarboxylase family, to which also isocitrate dehydrogenase, homoisocitrate dehydrogenase, tartarate dehydrogenase and malic enzyme belong (cf. review [1]). In spite of differences in the Rgroups of their substrates, all enzymes of the family catalyse the same two-step reaction: a pyridine nucleotide dependent reversible oxidation followed by an irreversible decarboxylation step (Scheme 1). IPMDH is part of the leucine biosynthesis pathway and catalyses the oxidation and decarboxylation of (2R,3S)-3-isopropylmalate (IPM) to 2-oxo-4-methyl-pentanoate with the help of $\mathrm{NAD}^{+}$and a divalent cation $\left(\mathrm{Mn}^{2+}\right.$ or $\left.\mathrm{Mg}^{2+}\right)$ [2]. IPMDH is an essential enzyme for the amino acid metabolism of bacteria, yeast and plants, but is absent in mammals, including humans. This qualifies IPMDH as a possible drug target against some bacteria.

Although functional studies on IPMDHs are rather scarce [3-6], several crystal structures of IPMDHs have been determined [7-11], including the crystal structures of IPMDH from the extremely thermophilic organism, Thermus thermophilus (Tt) [12-17]. In terms of fold and quaternary structure, IPMDHs from the various origins exhibit great similarities. In all cases observed so far, IPMDHs form a symmetric homodimer (Figure 1A) whose subunits can be divided into two structural domains (Figure 1B). For a topology diagram of the structure and the naming convention of its various structure elements see Figure 1 in Gráczer et al. [17]. Two important regions located in the interdomain region have been identified (Hinge 1 and Hinge 2, cf. Figure 1B), which are responsible for the opening and closing of the two domains during the reaction [17].

While the structures of complexes of IPMDH with $\mathrm{NAD}^{+}$or NADH $[13,14,16,17]$, and complexes with $\mathrm{Mn}^{2+}$ and IPM have been determined [8, 11, 17], no crystal structure of IPMDH in complex with both bound substrates has been reported so far. The nucleotide substrate, $\mathrm{NAD}^{+}$or the product, NADH has been known to bind to a specific nucleotide binding loop on one of the two structural domains $[13,17]$ and IPM resides between the two domains bound by amino acid sidechains of both subunits $[8,17]$. Substrate binding induces domain closure, albeit to a different extent in different complexes. As is the case for other multidomain enzymes [18, 19] including the $\beta$ hydroxy-decarboxylase family [20], domain movements play an essential role in IPMDH's catalytic cycle. 
A multiple sequence alignment of the members of $\beta$-hydroxyacid oxidative decarboxylase family indicates a high degree of sequence similarity [1]. The conserved Tyr139 of Tt IPMDH, for instance, has been suggested from a mutagenesis study to serve as a general acid that might promote the keto-enol tautomerisation after decarboxylation [21]. No experimental evidences have yet been obtained concerning the roles of other conserved active site residues of $T t$ IPMDH, such as Lys185 and the three metal-binding aspartates in the active site (Asp217, Asp241, Asp245), although, in analogy to isocitrate dehydrogenase [22], their participation in a proton relay from the substrate to the bulk solvent through a catalytic triad (Tyr-Asp-Lys) can be assumed [20]. Furthermore, the three conserved arginines, Arg94, Arg104 and Arg132 in the active site of $T t$ IPMDH are important to bind carboxylates of the substrate IPM electrostatically [17]. A mutagenesis study revealed that Arg 94 also facilitates the stabilization of the transition state in the decarboxylation reaction [23]. Based on the sequence similarities, it appears that in spite of the differences in the R-groups of their substrates, all enzymes of the family catalyse the reaction according to the same principles.

In this study, the crystal structure of the unproductive quaternary complex $T t$-IPMDH$\mathrm{Mn}^{2+}$-IPM-NADH was determined at high resolution. The relative position and orientation of the two reacting substrates as deduced from this crystal structure poses the question, whether this arrangement presents a reasonable model of the reactant complex for the chemical reaction. In order to find an answer to this question, molecular dynamics simulations and $a b$ initio $\mathrm{QM} / \mathrm{MM}$ calculations on the hydride-transfer reaction, which is probably the rate-limiting step of the overall reaction, were undertaken. No such computational studies have yet been made with the other potentially active crystallographic structures of related enzymes, such as isocitrate dehydrogenase [20], tartrate dehydrogenase [24] and malic enzyme [25].

\section{RESULTS and DISCUSSION}

Tt-IPMDH overall structure. As is evident from the refinement statistics presented in Table 1, the structure is well refined and of high general quality. The four individual protein chains in the asymmetric unit of the crystal are very similar to each other with r.m.s. differences between the chains of about $0.2 \AA$, which is not significantly larger than the overall coordinate error of the structure. Each of the four chains harbors one NADH, one IPM, one $\mathrm{Mn}^{2+}$ and two $\mathrm{K}^{+}$ions, one of them bound close to the active site. The chains A-D assemble into two functional dimers (AB and $C D$ ), which both exhibit a fully closed conformation, only slightly better closed than the previously published structure of the ternary complex $T t$-IPMDH-Mn ${ }^{2+}$-IPM [17]. Overlaying of the various open, partially and fully closed forms are illustrated by Fig. 2A and 2B. The very same closed conformation was observed in a different crystal form (data not shown), which lends support to the biological relevance of this conformation. 
The quality of the structure is also illustrated by the observed electron densities of the substrate IPM, $\mathrm{Mn}^{2+}$ and the co-factor product NADH (Figure 3). The nicotinamide ring of the NADH is placed right above the substrate IPM with $3.0 \AA$ distance between the $\mathrm{C} 2$ atom of IPM and the C4N atom of NADH. The fit of the ligands to the electron densities are excellent.

A surprising observation was that despite the fact that NADH was used in the crystallization experiment, the nicotinamide ring appears to be completely planar. Experimental evidence for this is shown in Figure 3, where the omit difference electron density of the NADH is displayed. Further evidence for the planarity of the nicotinamide ring is obtained when the dinucleotide is refined without any restraints (data not shown). Even in this case the nicotinamide ring stays planar and does not assume any puckered conformation as would be expected for NADH. There are two possible explanations for this phenomenon. The first is that NADH was somehow converted to $\mathrm{NAD}^{+}$during the crystallization or the diffraction experiment and the second is that the protein conformation imposes planarity of the ring by steric pressure. While we cannot rule out the first explanation, it seems more likely to us that the enzyme imposes planarity of the nicotinamide ring. This would effectively enhance $\mathrm{NAD}^{+}$binding over NADH-binding and could serve as a mechanism to release NADH after the reaction is completed.

Tt-IPMDH active site architecture. The active site of IPMDH is located in a cavity between the two domains of one subunit (Figure 4). While $\mathrm{Mn}^{2+}$ and IPM bind mostly to residues of domain 2, NADH binds almost exclusively to residues of domain 1. The details of the substrate binding at the level of side-chain interactions are illustrated by Figures 5A and 5B. The complete list of the atomic distances (except the hydrophobic contacts) are summarized in Table 2. It is also important to note that amino acid residues from the second subunit of the dimeric enzyme, in particular Lys185' (the prime denotes that the side chain belongs to the other subunit), complete the active site arrangement of the first subunit. Lys185' and Asn187' are located in a loop between $\alpha f^{\prime}$ and $\beta I^{\prime}$ that extends across the subunit interface, as described in the previous structural work [17]. Furthermore, Asp217' (Figure 5) is located in a helix ( $\left.\alpha g^{\prime}\right)$ at the subunit inteface.

In the fully closed structure presented here, the nicotinamide ring of the NADH is placed right above the substrate IPM with a distance between the C2 atom of IPM and the C4N atom of NADH of about $3.0 \AA$ (Figure 3). This distance is much shorter than even the shortest possible van der Waals contacts and requires some energy to achieve. The very short distance already suggests a partial overlap of the electron clouds of the two atoms and it seems feasible that such an arrangement would support the anticipated hydride transfer reaction. Another consequence of bringing the substrates into close proximity for reaction is that the enzyme forces the conformation of the substrate IPM away from its equilibrium state. In the quaternary complex the C1-C2-C3-C5 dihedral angle of IPM is - 
$149^{\circ}$ (Figure 6A), while in the ternary complex (without NADH, [17]) it is $-175^{\circ}$ (Figure 6B), This distortion may also be relevant to facilitate the chemical reaction.

The reaction mechanism of IPMDH: QM/MM calculations. The reaction mechanism of oxidative decarboxylating enzymes consists of two major steps: (i) the redox reaction including a hydride transfer from the substrate to the co-factor $\mathrm{NAD}^{+}$resulting in the formation of an $\alpha$-ketocarboxylic acid and NADH and (ii) an entropically-driven decarboxylation step leading to the final product. Since the redox step is most probably the rate-limiting step of the overall reaction, the focus of this study was laid on it. The redox-step may be further dissected into the deprotonation of the 2hydroxyl group of the substrate and the actual hydride transfer. Consequently, in order to describe the reaction mechanism in detail, the following three questions need to be answered: (i) What is the ultimate proton acceptor in the deprotonation step of the reaction? (ii) What occurs first: deprotonation or hydride transfer? and (iii) Which is the rate-limiting step and how large are the barriers of the two processes?

The identity of the general base. As mentioned in the introduction, the active site of IPMDH contains several basic residues (Arg94, Arg104, Arg132, Lys185' etc.), as well as a divalent cation: either $\mathrm{Mn}^{2+}$ or $\mathrm{Mg}^{2+}$. Partial charge balance is achieved by the presence of a few acidic residues (Asp217', Asp241 and Asp245) coordinating to the cation [17]. Nevertheless, the overall charge in the active site is positive, which certainly facilitates the binding of the negatively charged IPM. In the case of malate dehydrogenase [26], 6-phosphogluconate dehydrogenase [27, 28] and various isocitrate-dehydrogenase enzymes [20,29] it has been proposed that the nearby lysine residue previously deprotonated by an aspartic acid residue could act as a general base to remove the 2hydroxyl proton of the substrate. Indeed, in the obtained structure of IPMDH the basic nitrogen atom of Lys185' is located at a distance of around $3 \AA$ from the 2-hydroxyl group suggesting its possible role as a base. The predicted $\mathrm{pKa}$ values of this Lys $185^{\prime}$ are 5.9 in the absence and 8.1 in the presence of IPM. Although these predicted values may have to be taken with a grain of salt, they show that binding of IPM can shift the $\mathrm{pKa}$ value of Lys185' to a sufficiently high value thus lending support to the hypothesis that Lys185' is the general base [30]. It may therefore be assumed that prior to IPM binding Lys $185^{\prime}$ is deprotonated; it can then act as the base to take up the proton from the 2-hydroxyl group of IPM. It this context, another important aspect is whether Lys185' directly deprotonates the hydroxyl group of IPM or whether deprotonation occurs via a water-assisted proton shuttle process. Water molecules have been suggested to play a role in the deprotonation of the substrate in various enzyme complexes [31-34] and proton shuttle processes via water molecules usually occur through a very low barrier. In the structure a water molecule is indeed present in each subunit (w2013 in both chains A and B) very close (less than $3.1 \AA$ ) to both of the 2-hydroxyl group of IPM and to Lys185' (Figure 5 and Table 2). During the molecular dynamics simulations the water molecule w2013 did not 
exchange with bulk solvent indicating its structural and functional relevance for the deprotonation process.

Reaction mechanism of the hydride transfer and deprotonation steps. The first question, which needs to be answered, is the sequence of events: does deprotonation occur before, after or simultaneously with the hydride transfer? The QM/MM calculations carried out in this study demonstrate convincingly that the deprotonation of the hydroxyl group of the substrate IPM occurs very easily and that deprotonation is a prerequisite of the hydride transfer step. Only after deprotonation, the electrons locked in the $\mathrm{O}-\mathrm{H}$ bond of the hydroxyl group are mobilized, and are therefore able to allow the hydride transfer to occur in the next step (cf. Scheme 2). Proton transfer from the IPM-OH group via the above mentioned catalytic water molecule to Lys $185^{\prime}$ occurs with a very low energy barrier (2.7-4.5 kcal/mol, see Figure 7). This is significantly lower than the barrier of $7 \mathrm{kcal} / \mathrm{mol}$ obtained earlier for malate dehydrogenase in another computational study [35]. The intermediate (I) formed in this proton shuttle process is slightly lower in energy (by -0.5 to $-7.5 \mathrm{kcal} / \mathrm{mol})$ than the reactant complex. In this proton shuttle process the two protons $\left(\mathrm{H}_{\mathrm{p}}\right.$ originating on the 2-hydroxyl group of IPM and $\mathrm{H}_{w}$ originally belonging to the water molecule) move in a concerted fashion (cf. Figures $8 \mathrm{~A}$ and $8 \mathrm{~B}$ ). The deprotonation process is facilitated by the presence of the $\mathrm{Mg}^{2+} / \mathrm{Mn}^{2+}$ cation as it interacts with the 2-hydroxyl group of IPM and stabilizes the negative charge accumulating on the $\mathrm{O}$-atom. The low barrier of the reaction, and low energy of this intermediate implies that this process can occur easily, most likely also in the absence of $\mathrm{NAD}^{+}$. It may therefore be proposed that this proton transfer occurs already upon IPM binding to the active site, independent of the presence of $\mathrm{NAD}^{+}$. As mentioned above, the hydride transfer is, most probably, the rate-limiting step of the reaction (cf. transfer of $\mathrm{H}_{\mathrm{h}}$ as depicted in Figures $8 \mathrm{C}, 8 \mathrm{D}$ and $8 \mathrm{E}$ ). Values of $14.4-18.3 \mathrm{kcal} / \mathrm{mol}$ were obtained for the energy of the intermediate after the deprotonation step (see the value of TS2* in Table 3). Zero-point energy corrections to the barrier would lower this barrier by about $3 \mathrm{kcal} / \mathrm{mol}$ based on previous studies of hydride transfer reactions [36]. It can therefore be estimated that the barrier of this process is about $12-15 \mathrm{kcal} / \mathrm{mol}$, which is in good agreement with the calculated activation energy of $15 \mathrm{kcal} / \mathrm{mol}$ for the hydride transfer step of malate dehydrogenase enzyme [35]. The structure of the transition state and the obtained product are qualitatively shown in Figure 8 .

A further interesting aspect of the obtained quaternary structure is the $\mathrm{C} 1-\mathrm{C} 2-\mathrm{C} 3-\mathrm{C} 5$ dihedral angle of the IPM molecule. In the Tt-IPMDH-Mn ${ }^{2+}$ IPM ternary complex structure this dihedral angle was about $-175^{\circ}$, while in the quaternary structure it is $-149^{\circ}$ in chain A (cf. Figure $6 \mathrm{~A}$ ) and $-142^{\circ}$ in chain B. Therefore, a potential energy surface scan around this dihedral angle in IPM was performed. In the $-180^{\circ}$ to $-140^{\circ}$ region, the rotation around the $\mathrm{C} 2-\mathrm{C} 3$ bond can occur very easily (with a barrier of less than $1 \mathrm{kcal} / \mathrm{mol}$ ), implying that even weak secondary forces (e.g. dispersion) may be able to change its value. It is striking however, that in the $\mathrm{QM} / \mathrm{MM}$ profile calculations the value of the 
dihedral angle decreases from about $-175^{\circ}$ in the reactant complex to about $-160^{\circ}$ in the product state in each of the studied reaction profiles. This decrease may originate from the favourable dispersion interaction between the nicotinamide ring of NADH and the isopropyl group of IPM. It is also noteworthy that the dihedral angle of IPM bound to the quaternary structure is already close to that of the final reaction product, which can be observed in a further crystal structure of $T t$-IPMDH in complex with its reaction products (Palló, A. and Weiss, M.S., unpublished work). A similar stereochemistry of the mechanism has been also established for the closely related ICDH, where the hydride-ion should be similarly transferred onto the re face of the coenzyme [37].

The activating role of $\mathrm{K}^{+}$. In the active site of the quaternary complex a potassium ion was identified. It is coordinated by the main chain carbonyl O-atom of Gly70, the side-chain OG of Ser71 from the $\beta$-strand $\mathrm{C}$, and by the side-chain carboxylate of Glu270 as well as the main chain O-atoms of Pro271 and His273 from the nucleotide-binding loop (Figure 5B). Further, the amide $\mathrm{N}$-atom of the nicotinamide ring is positioned right above the $\mathrm{K}^{+}$-site at a distance of $2.7 \AA$. Activation of IPMDH by $\mathrm{K}^{+}$has been known for a long time [4], but its structural background has not been explained. It seems to be a characteristic feature of IPMDH as no activation by $\mathrm{K}^{+}$was observed for the homologue enzyme ICDH [38]. It may be hypothesized that the $\mathrm{K}^{+}$-ion increases the electron-withdrawing ability of the amide-group of $\mathrm{NAD}^{+}$through electrostatic interactions. This would then in turn increase the electrophilic character of the nicotinamide ring and thereby facilitate the hydride transfer reaction.

In order to provide support for our hypothesis, the $\mathrm{QM} / \mathrm{MM}$ energy profile calculations were repeated for the $\mathrm{Mn}^{2+}$-containing systems QM2 by setting the charge of $\mathrm{K}^{+}$to zero. The most important benefit of this approach was that it allowed us to selectively study the influence of $\mathrm{K}^{+}$on the energy barrier of the hydride transfer reaction, since all other factors (e.g. geometric factors) were nearly identical in the corresponding profiles. The calculations revealed that the barrier of the proton transfer was not significantly affected by the presence of $\mathrm{K}^{+}$. However, the intermediate of the reaction was less stable by about $3 \mathrm{kcal} / \mathrm{mol}$ in the absence of $\mathrm{K}^{+}$, and the barrier of the hydride transfer reaction turned out to be about $4-6 \mathrm{kcal} / \mathrm{mol}$ higher. According to the Arrhenius equation this corresponds to a 1000-2000 fold increase in the reaction rate in the presence of $\mathrm{K}^{+}$. It should, however, be noted that this is an upper estimate of the rate acceleration caused by $\mathrm{K}^{+}$, as in a real system the position of $\mathrm{K}^{+}$might be taken over by other cations present in the solution, thereby slightly compensating for the lack of $\mathrm{K}^{+}$. In fact, the $k_{\text {cat }}$ value of the $T t$ IPMDH catalysed reaction is decreased from $230 \mathrm{~min}^{-1}$ to $15 \mathrm{~min}^{-1}$ when $30 \mathrm{mM} \mathrm{K}$ present in the assay mixture, was replaced by $\mathrm{Na}^{+}$ (Gráczer, É., Palló, A., Oláh, J., Szimler, T., Konarev, P.V., Svergun, D.I., Závodszky, P., Weiss, M.S. and Vas, M., unpublished work).

As a conclusion, based on the high resolution X-Ray structure of the quaternary nonproductive complex of IPMDH, which provided a snapshot of the relative geometry of the substrates before the reaction, and $\mathrm{QM} / \mathrm{MM}$ calculations, the reaction mechanism of the oxidative 
decarboxylation reaction catalyzed by IPMDH could be elucidated in detail. The first step of the reaction is the deprotonation of the OH-group of IPM with a low energy barrier of 2.7-4.5 kcal/mol. The central roles here are attributed to a water molecule and to the side-chain of Lys185', the latter acting as a general base in the deprotonation reaction. Next along the reaction profile is the hydride transfer from the $\mathrm{C} 2$ atom of IPM to the $\mathrm{C} 4 \mathrm{~N}$ atom of $\mathrm{NAD}^{+}$with a higher energy barrier of 12-15 $\mathrm{kcal} / \mathrm{mol}$. The calculations showed that the presence of $\mathrm{K}^{+}$accelerates the hydride transfer reaction by about 1000-2000 fold. The final step, the decarboxylation reaction is known to happen spontaneously with a very low energy barrier. Due to the production of $\mathrm{CO}_{2}$, the last reaction step drives the equilibrium of the reaction towards the products.

\section{MATERIALS and METHODS}

Reagents Threo-DL-3-isopropylmalic acid (IPM) was purchased form Wako Biochemicals GmbH (Neuss, Germary), $\mathrm{NAD}^{+}$and $\mathrm{NADH}$ were Sigma (St. Louise, Missouri, USA) products. Isopropyl-1-thio- $\beta$-D-galactopyranoside (IPTG) (Fermentas, Thermo Fisher Scientific Inc., Waltham, M.A., USA), chloramphenicol, and ampicillin (Sigma) were used for fermentation. Chromatography media were obtained from GE Healthcare (Little Chalfont, UK).

Structure determination and refinement. The C-terminally His-tagged variant of Tt-IPMDH was expressed and purified as described earlier [39]. Pure lyophilized Tt-IPMDH was dissolved in distilled water to a concentration of $30.8 \mathrm{mg} / \mathrm{ml}$. Crystals were obtained within 3 days using the hanging drop method at $20^{\circ} \mathrm{C}$ by mixing $1 \mu 1$ protein solution consisting of $20.5 \mathrm{mg} / \mathrm{ml} \mathrm{Tt}$-IPMDH, $13.3 \mathrm{mM} \mathrm{MnCl} 2,9.0 \mathrm{mM}$ IPM and $4.9 \mathrm{mM} \mathrm{NADH}$ with $1 \mu 1$ reservoir solution consisting of $20 \%$ (w/v) PEG 6000, 0.1 M MOPS/KOH pH 7.6, and 10\% (v/v) ethanol. Diffraction data to $2.0 \AA$ resolution were collected from a single crystal on beamline BL14.1 of the Helmholtz-Zentrum Berlin (Germany) [40]. The data were processed using XDS [41] and the structure was determined using MOLREP [42] and the ternary complex structure of $T t$-IPMDH-Mn ${ }^{2+}$-IPM [17] (PDB entry 2Y41) as a search model. Atomic coordinates were refined using REFMAC5 [43] and manually inspected using COOT [44]. All relevant statistics are presented in Table 1. The refined structure and the corresponding structure factor amplitudes were deposited with the PDB under Database ID: 4F7I.

$Q M / M M$ calculations. For all modeling studies, the chains A and B of the PDB entry 4F7I reported here have been selected. NADH was transformed into $\mathrm{NAD}^{+}$at the beginning of the system setup. Hydrogen atoms were added to the initial enzyme/substrate complexes, and their positions were optimized. The protonation states of acid and basic residues were predicted by using the PROPKA2.0 program [45, 46]. Glu133 and Glu155 were protonated and Lys185 was deprotonated in all simulations. All histidine residues were $\delta$-protonated. The structures were solvated within a $60 \AA$ box 
with 8000 pre-equilibrated water molecules, represented by the TIP3P model, centered on the C2 carbon atom of IPM found in Chain B. The added water was then equilibrated by stochastic boundary $\mathrm{MD}$ at $300 \mathrm{~K}$ over $20 \mathrm{ps}$ with respect to the substrate-bound enzyme structure and minimized. Water molecules more than $25 \AA$ from the $\mathrm{C} 2$ carbon atom of IPM were removed. Then, all atoms within a $25 \AA$ sphere around C2 carbon atom of IPM were minimized, followed by stochastic boundary MD simulation of the whole system. Atoms farther than $25 \AA$ from the $\mathrm{C} 2$ carbon atom of IPM were fixed throughout the simulations following the scheme proposed by van der Kamp [47]. All systems were heated to $300 \mathrm{~K}$ over $60 \mathrm{ps}$. Subsequent MD equilibrations at $300 \mathrm{~K}$ were carried out over $5000 \mathrm{ps}$. The CHARMM27 force field [48] has been used for protein and water molecules, while IPM was described by the CHARMM General Force Field (CGenFF) [49]. Atom typing and assignment of parameters and charges by analogy $[50,51]$ for IPM were done using the Paramchem interface [52]. The penalty scores obtained for parameters and charges indicated were very low in each case (less than 10) indicating the transferability of the parameters. All modeling calculations were carried out using the CHARMM software package [53].

The trajectory file of the MD simulation was analysed and several starting structures based on geometrical criteria were selected from the trajectory file of the MD simulation for the QM/MM calculations, similarly to previous works $[36,54]$. Initial structures with short distances between C4N of $\mathrm{NAD}^{+}$and $\mathrm{H}_{\mathrm{P}}$ (the transferable hydrogen) of IPM were chosen. Reaction energy profiles were generated by performing $\mathrm{QM} / \mathrm{MM}$ energy minimization with a restraint (force constant: 4000 $\mathrm{kcal} / \mathrm{mol} / \AA^{2}$ ) corresponding to the reaction coordinate. In the case of the proton transfer reaction the reaction coordinate was the sum of two distances: the distance of $\mathrm{H}_{\mathrm{p}}(\mathrm{IPM})-\mathrm{O}_{\mathrm{w}}$ (catalytic water) and the distance of $\mathrm{H}_{\mathrm{w}}$ (catalytic water)-NZ(Lys185). Its value decreased from about $3.18 \AA$ in the reactant complex to about 2.08 A. in the intermediate state. In the case of the hydride transfer reaction the distance of $\mathrm{H}_{h}$ (of IPM) and C4N of $\mathrm{NAD}^{+}$was used as reaction coordinate whose value was systematically decreased from $2.10 \AA$ in the intermediate state to about $1.12 \AA$ in the product complex. In all cases forward and backward iterations along the reaction coordinates were carried out to obtain hysteresis free reaction profiles. The structure of the minima along the reaction profiles (i.e. of the reactant, intermediate and product states) was optimized without any restrain and the structures corresponding to the maxima of the obtained energy profiles were considered as transition states. One of the structures was selected as a starting structure for studying the two-dimensional potential energy surface of the hydride and proton transfer reactions, for which the two restrains mentioned above were used.

Three different atom partitioning schemes QM1-3 were tested. In each case, care was taken to avoid cutting polar bonds. The charges of MM atoms (and the groups they belong to) bonded to QM atoms were set to zero in order to avoid unphysical effects due to the strong polarization of the QM wave function due to the proximity of large point charges. The smallest QM-region tested (QM1) 
contained the nicotinamide ring of $\mathrm{NAD}^{+}$, the IPM molecule, Lys185' (the prime denotes the side chain from the other subunit) and a water molecule (w2013) located close to both IPM and Lys185'. As the calculations on QM1 indicated a rather large favorable MM contribution to the activation energy of the system, arising from charge-charge interactions, the calculations were repeated using larger QM regions. QM2 contained in addition to the atoms of QM1 the side-chains of Arg132 and Tyr139, as well as the $\mathrm{Mn}^{2+}$ ion including its first solvation shell (the carboxyl and $\beta$-methylene group of Asp217' and of Asp 241 and two additional water molecules). QM2 thus contained 102 atoms and 6 link atoms. The largest QM-region investigated, QM3, contained in addition the side chains of Arg94 and Arg104. However, the inclusion of these two amino acids did not result in any significant differences compared to QM2; consequently, QM2 was used in all remaining calculations. All $\mathrm{QM} / \mathrm{MM}$ calculations were repeated using magnesium ions instead of manganese ions, in order to test the effect of the identity of the metal ion. These calculations also included the QM/MM optimization of all structures along the reaction profiles. The potassium ion was described by the molecular mechanics force field, more specifically by its charge and Lennard-Jones parameters, which are known to provide a good description of the non-bonding interaction of $\mathrm{K}^{+}$. The positions of atoms being further than $20 \AA$ from the $\mathrm{C} 2$ of IPM were fixed in the QM/MM optimizations and the charges of atoms further than $25 \AA$ from the C2 of IPM were set to zero. Energy and force calculations on the QM region were carried out with the Gaussian 09 software package [55] with the B3LYP functional in conjunction with the $6-31 \mathrm{G}^{*}$ basis set on all atoms with the exception of manganese for which the SDD ECP and basis set were used. Through electronic embedding of the point charges representing the protein environment in the Hamiltonian of the QM calculation, the electrostatic interaction among atoms of the $\mathrm{QM}$ and $\mathrm{MM}$ regions has been taken into account.

The MM region was modeled using the TINKER program $[56,57]$ and the CHARMM27 force field [48]. The QoMMMa program [58], was used to couple the input and output files generated by the Gaussian 09 and TINKER program packages.

Single point calculations were carried out on the critical points of the energy profiles (reactants, products and transition states) to investigate the effect of basis set size at the B3LYP/6$311++\mathrm{G}^{* *} / \mathrm{MM}$ level of theory. Calculations on $\mathrm{Mg}^{2+}$ containing systems were carried out using a restricted Kohn-Sham formalism, while the $\mathrm{Mn}^{2+}$ containing systems were studied in the sextet spin state described by an unrestricted $\mathrm{KS}$ formalism. The QM/MM calculations employed a dispersion correction using the DFT-D3 program [59].

\section{ACKNOWLEDGEMENTS}

We gratefully acknowledge the sincere support by Profs. G. Pálinkás and M. Czugler (Research Centre of Natural Sciences, HAS, Budapest). We also thank Prof. J. N. Harvey (School of Chemistry, University of Bristol) for useful discussions on the QM/MM calculations. This work was 
supported by various funding organizations: We thank the National Science and Technology Office (Hungary) for an X-ray diffractometer purchase grant (MU-00338/2003), Boehringer Ingelheim Fonds (travel grant for AP), EU Marie Curie ERG Fellowship (Project "Oestrometab", for JO), the New Széchenyi Plan (TÁMOP-4.2.2/B-10/1-2010-0009), Hungarian Scientific Research Funds (OTKA NK 108642 and K 75869). We also thank the synchrotron facilities at Helmholtz Zentrum Berlin (Germany) for the allocation and provision of synchrotron beam time.

\section{AUTHOR CONTRIBUTION STATEMENT}

AP, ÉG and AM performed X-ray experiments and analysed the data. JO carried out QM/MM calculations, interpreted the results and contributed to preparation of the manuscript. PZ, MW and MV organized and conducted the study, interpreted the results and prepared the manuscript. 


\section{REFERENCES}

1. Aktas DF \& Cook PF (2009) A lysine-tyrosine pair carries out acid-base chemistry in the metal ion-dependent pyridine dinucleotide-linked $\beta$-hydroxyacid oxidative decarboxylases. Biochemistry 48, 3565-3577.

2. Hayashi-Iwasaki Y \& Oshima T (2000) Purification and characterization of recombinant 3isopropylmalate dehydrogenases from Thermus thermophilus and other microorganisms. Methods Enzymol 324, 301-322.

3. Dean AM \& Dvorak L (1995) The role of glutamate 87 in the kinetic mechanism of Thermus thermophilus isopropylmalate dehydrogenase. Protein Sci 4, 2156-2167.

4. Yamada T, Akutsu N, Miyazaki K, Kakinuma K, Yoshida M \& Oshima T (1990) Purification, catalytic properties, and thermal stability of threo-Ds-3-isopropylmalate dehydrogenase coded by leuB gene from an extreme thermophile, Thermus thermophilus strain HB8. J Biochem (Tokyo) 108, 449-456.

5. Wallon G, Yamamoto K, Kirino H, Yamagishi A, Lovett ST, Petsko GA \& Oshima T (1997) Purification, catalytic properties and thermostability of 3-isopropylmalate dehydrogenase from Escherichia coli. Biochim Biophys Acta 1337, 105-112.

6. Gráczer É, Lionne C, Závodszky P, Chaloin L \& Vas M (2013) Transient kinetic studies reveal isomerization steps along the kinetic pathway of Thermus thermophilus 3-isopropylmalate dehydrogenase. FEBS J 280, 1764-1772.

7. Wallon G, Kryger G, Lovett ST, Oshima T, Ringe D \& Petsko GA (1997) Crystal structures of Escherichia coli and Salmonella typhimurium 3-isopropylmalate dehydrogenase and comparison with their thermophilic counterpart from Thermus thermophilus. J Mol Biol 266, 1016-1031.

8. Imada K, Inagaki K, Matsunami H, Kawaguchi H, Tanaka H, Tanaka N \& Namba K (1998) Structure of 3-isopropylmalate dehydrogenase in complex with 3-isopropylmalate at 2.0 A resolution: the role of Glu88 in the unique substrate-recognition mechanism. Structure 6, 971-982.

9. Tsuchiya D, Sekiguchi T \& Takenaka A (1997) Crystal structure of 3-isopropylmalate dehydrogenase from the moderate facultative thermophile, Bacillus coagulans: two strategies for thermostabilization of protein structures. J Biochem (Tokyo) 122, 1092-1104.

10. Singh RK, Kefala G, Janowski R, Mueller-Dieckmann C, von Kries JP \& Weiss MS (2005) The high-resolution Structure of LeuB (Rv2995c) from Mycobacterium tuberculosis. J Mol Biol 346, $1-11$.

11. Nagae T, Kato C \& Watanabe N (2012) Structural analysis of 3-isopropylmalate dehydrogenase from the obligate piezophile Shewanella benthica DB21MT-2 and the nonpiezophile Shewanella oneidensis MR-1. Acta Crystallogr Sect F Struct Biol Cryst Commun 68, 265-268. 
12. Imada K, Sato M, Tanaka N, Katsube Y, Matsuura Y \& Oshima T (1991) Three-dimensional structure of a highly thermostable enzyme, 3-isopropylmalate dehydrogenase of Thermus thermophilus at 2.2 A resolution. J Mol Biol 222, 725-738.

13. Hurley JH \& Dean AM (1994) Structure of 3-isopropylmalate dehydrogenase in complex with NAD+: ligand-induced loop closing and mechanism for cofactor specificity. Structure 2, $1007-$ 1016.

14. Kadono S, Sakurai M, Moriyama H, Sato M, Hayashi Y, Oshima T \& Tanaka N (1995) Ligand-induced changes in the conformation of 3-isopropylmalate dehydrogenase from Thermus thermophilus. J Biochem (Tokyo) 118, 745-752.

15. Nagata C, Moriyama H, Tanaka N, Nakasako M, Yamamoto M, Ueki T \& Oshima T (1996) Cryocrystallography of 3-Isopropylmalate dehydrogenase from Thermus thermophilus and its chimeric enzyme. Acta Crystallogr D Biol Crystallogr 52, 623-630.

16. Nango E, Yamamoto T, Kumasaka T \& Eguchi T (2009) Crystal structure of 3isopropylmalate dehydrogenase in complex with $\mathrm{NAD}(+)$ and a designed inhibitor. Bioorg Med Chem 17, 7789-7794.

17. Gráczer É, Merli A, Singh RK, Karuppasamy M, Závodszky P, Weiss MS \& Vas M (2011) Atomic level description of the domain closure in a dimeric enzyme: Thermus thermophilus 3isopropylmalate dehydrogenase. Mol Biosyst 7, 1646-1659.

18. Hayward S (2004) Identification of specific interactions that drive ligand-induced closure in five enzymes with classic domain movements. J Mol Biol 339, 1001-1021.

19. Gerstein M \& Echols N (2004) Exploring the range of protein flexibility, from a structural proteomics perspective. Curr Opin Chem Biol 8, 14-19.

20. Goncalves S, Miller SP, Carrondo MA, Dean AM \& Matias PM (2012) Induced fit and the catalytic mechanism of isocitrate dehydrogenase. Biochemistry 51, 7098-7115.

21. Miyazaki K \& Oshima T (1993) Tyr-139 in Thermus thermophilus 3-isopropylmalate dehydrogenase is involved in catalytic function. FEBS Lett 332, 37-38.

22. Grodsky NB, Soundar S \& Colman RF (2000) Evaluation by site-directed mutagenesis of aspartic acid residues in the metal site of pig heart NADP-dependent isocitrate dehydrogenase. Biochemistry 39, 2193-2200.

23. Fujita M, Toyooka Y, Tamegai H, Eguchi T \& Kakinuma K (2000) Arg-94 is crucial to the catalysis of 3-isopropylmalate dehyrdogenase from Thermus thermophilus HB8. J Mol Catal B 9, 149-155.

24. Malik R \& Viola RE (2010) Structural characterization of tartrate dehydrogenase: a versatile enzyme catalyzing multiple reactions. Acta Crystallogr D Biol Crystallogr 66, 673-684.

25. Tao X, Yang Z \& Tong L (2003) Crystal structures of substrate complexes of malic enzyme and insights into the catalytic mechanism. Structure 11, 1141-1150. 
26. Karsten WE, Liu D, Rao GS, Harris BG \& Cook PF (2005) A catalytic triad is responsible for acid-base chemistry in the Ascaris suum NAD-malic enzyme. Biochemistry 44, 3626-3635.

27. Berdis AJ \& Cook PF (1993) Chemical mechanism of 6-phosphogluconate dehydrogenase from Candida utilis from $\mathrm{pH}$ studies. Biochemistry 32, 2041-2046.

28. Price NE \& Cook PF (1996) Kinetic and chemical mechanisms of the sheep liver 6phosphogluconate dehydrogenase. Arch Biochem Biophys 336, 215-223.

29. Quartararo CE, Hazra S, Hadi T \& Blanchard JS (2013) Structural, Kinetic and Chemical Mechanism of Isocitrate Dehydrogenase-1 from Mycobacterium tuberculosis. Biochemistry 52, 17651775 .

30. Bas DC, Rogers DM \& Jensen JH (2008) Very fast prediction and rationalization of pKa values for protein-ligand complexes. Proteins 73, 765-783.

31. Wallin G \& Aqvist $J$ (2010) The transition state for peptide bond formation reveals the ribosome as a water trap. Proc Natl Acad Sci US A 107, 1888-1893.

32. Acosta-Silva C, Bertran J, Branchadell V \& Oliva A (2012) Quantum-mechanical study on the mechanism of peptide bond formation in the ribosome. J Am Chem Soc 134, 5817-5831.

33. Miscione GP, Calvaresi M \& Bottoni A (2010) Computational evidence for the catalytic mechanism of caspase-7. A DFT investigation. $J$ Phys Chem B 114, 4637-4645.

34. Chen L, Kong X, Liang Z, Ye F, Yu K, Dai W, Wu D, Luo C \& Jiang H (2011) Theoretical study of the mechanism of proton transfer in the esterase EstB from Burkholderia gladioli. $J$ Phys Chem B 115, 13019-13025.

35. Cunningham MA, Ho LL, Nguyen DT, Gillilan RE \& Bash PA (1997) Simulation of the enzyme reaction mechanism of malate dehydrogenase. Biochemistry 36, 4800-4816.

36. Kramos B, Menyhard DK \& Oláh J (2012) Direct hydride shift mechanism and stereoselectivity of P450nor confirmed by QM/MM calculations. J Phys Chem B 116, 872-885.

37. Grissom CB \& Cleland WW (1988) Isotope effect studies of the chemical mechanism of pig heart NADP isocitrate dehydrogenase. Biochemistry 27, 2934-2943.

38. Miller SP, Goncalves S, Matias PM \& Dean AM (2014) Evolution of a transition state: role of lys 100 in the active site of isocitrate dehydrogenase. ChemBioChem 15, 1145-1153.

39. Gráczer É, Varga A, Hajdú I, Melnik B, Szilágyi A, Semisotnov G, Závodszky P \& Vas M (2007) Rates of unfolding, rather than refolding, determine thermal stabilities of thermophilic, mesophilic, and psychrotrophic 3-isopropylmalate dehydrogenases. Biochemistry 46, 11536-11549.

40. Mueller U, Darowski N, Fuchs MR, Forster R, Hellmig M, Paithankar KS, Puhringer S, Steffien M, Zocher G \& Weiss MS (2012) Facilities for macromolecular crystallography at the Helmholtz-Zentrum Berlin. J Synchrotron Radiat 19, 442-449.

41. Kabsch W (2010) Xds. Acta Crystallogr D Biol Crystallogr 66, 125-132.

42. CCP4 (1994) The CCP4 (Collaborative Computational Project Number 4) suite: programmes for protein vrystallography. Acta Crystallogr D40, 760-763. 
43. Murshudov GN, Vagin AA \& Dodson EJ (1997) Refinement of macromolecular structures by the maximum-likelihood method. Acta Crystallogr D Biol Crystallogr 53, 240-255.

44. Emsley P \& Cowtan K (2004) Coot: model-building tools for molecular graphics. Acta Crystallogr D Biol Crystallogr 60, 2126-2132.

45. Olsson MH, Søndergard CR, Rostkowski M \& Jensen JH (2011) PROPKA3: Consistent Treatment of Internal and Surface Residues in Empirical pKa predictions. J Chem Theor Comput 7, 525-537.

46. Søndergard CR, Olsson MH, Rostkowski M \& Jensen JH (2011) Improved Treatment of Ligands and Coupling Effects in Empirical Calculation and Rationalization of pKa Values. $J$ Chem Theor Comput 7, 2284-2295.

47. van der Kamp MW (2008) Modelling reactions and dynamics of Claisen enzymes. Chapter 4.6. University of Bristol, Bristol.

48. MacKerell AD, Jr., Banavali N \& Foloppe N (2000) Development and current status of the CHARMM force field for nucleic acids. Biopolymers 56, 257-265.

49. Vanommeslaeghe K, Hatcher E, Acharya C, Kundu S, Zhong S, Shim J, Darian E, Guvench O, Lopes P, Vorobyov I \& Mackerell AD, Jr. (2010) CHARMM general force field: A force field for drug-like molecules compatible with the CHARMM all-atom additive biological force fields. $J$ Comput Chem 31, 671-690.

50. Vanommeslaeghe K \& MacKerell AD, Jr. (2012) Automation of the CHARMM General Force Field (CGenFF) I: bond perception and atom typing. J Chem Inf Model 52, 3144-3154.

51. Vanommeslaeghe K, Raman EP \& MacKerell AD, Jr. (2012) Automation of the CHARMM General Force Field (CGenFF) II: assignment of bonded parameters and partial atomic charges. $J$ Chem Inf Model 52, 3155-3168.

52. https://www.paramchem.org.

53. Brooks BR, Brooks CL, 3rd, Mackerell AD, Jr., Nilsson L, Petrella RJ, Roux B, Won Y, Archontis G, Bartels C, Boresch S, Caflisch A, Caves L, Cui Q, Dinner AR, Feig M, Fischer S, Gao J, Hodoscek M, Im W, Kuczera K, Lazaridis T, Ma J, Ovchinnikov V, Paci E, Pastor RW, Post CB, Pu JZ, Schaefer M, Tidor B, Venable RM, Woodcock HL, Wu X, Yang W, York DM \& Karplus M (2009) CHARMM: the biomolecular simulation program. J Comput Chem 30, 1545-1614.

54. Oláh J, Mulholland AJ \& Harvey JN (2011) Understanding the determinants of selectivity in drug metabolism through modeling of dextromethorphan oxidation by cytochrome P450. Proc Natl Acad Sci U S A 108, 6050-6055.

55. Frisch MJ, Trucks GW, Schlegel HB, Scuseria GE, Robb MA, Cheeseman JR, Scalmani G, Barone V, Mennucci B, Petersson GA, Nakatsuji H, Caricato M, Li X, Hratchian HP, Izmaylov AF, Bloino J, Zheng G, Sonnenberg JL, Hada M, Ehara M, Toyota K, Fukuda R, Hasegawa J, Ishida M, Nakajima T, Honda Y, Kitao O, Nakai H, Vreven T, Montgomery JA, Jr., Peralta JE, Ogliaro F, Bearpark M, Heyd JJ, Brothers E, Kudin KN, Staroverov VN, Kobayashi R, Normand J, 
Raghavachari K, Rendell A, Burant JC, Iyengar SS, Tomasi J, Cossi M, Rega N, Millam NJ, Klene M, Knox JE, Cross JB, Bakken V, Adamo C, Jaramillo J, Gomperts R, Stratmann RE, Yazyev O, Austin AJ, Cammi R, Pomelli C, Ochterski JW, Martin RL, Morokuma K, Zakrzewski VG, Voth GA, Salvador P, Dannenberg JJ, Dapprich S, Daniels AD, Farkas Ö, Foresman JB, Ortiz JV, Cioslowski J \& Fox DJG, Inc., Wallingford CT (2009) Gaussian 09, Revision B.01. http://wwwgaussiancom $/ g \_$_tech $/ g \_$_ur $/ m$ _citationhtm.

56. TINKER \& Page. -H (accessed 5 October, 2011) Tinker - Software tools for molecular design.

57. Ren P, Wu C \& Ponder JW (2011) Polarizable Atomic Multipole-based Molecular Mechanics for Organic Molecules. J Chem Theory Comput 7, 3143-3161.

58. Harvey JN (2004) Spin-forbidden CO ligand recombination in myoglobin. Faraday Discuss 127, 165-177.

59. Grimme S, Antony J, Ehrlich S \& Krieg H (2010) A consistent and accurate ab initio parametrization of density functional dispersion correction (DFT-D) for the 94 elements H-Pu. $J$ Chem Phys 132, 154104. 
Tables

Table 1. Diffraction Data Collection and Processing and Structure Refinement Statistics. The numbers in parenthesis refer to the highest resolution shell.

\begin{tabular}{|c|c|}
\hline \multicolumn{2}{|c|}{ Data Collection and Processing } \\
\hline Wavelength $(\AA)$ & 0.91841 \\
\hline Crystal to detector distance (mm) & 197 \\
\hline Rotation range per image $\left(^{\circ}\right)$ & 0.2 \\
\hline Total rotation range $\left({ }^{\circ}\right)$ & 193 \\
\hline Exposure time per image (s) & 2.5 \\
\hline Space group & $\mathrm{C} 2$ \\
\hline Cell constants a, b, c, $\beta\left(\AA,{ }^{\circ}\right)$ & $148.34,50.72,178.24,93.09$ \\
\hline Resolution range & $48.0-2.00(2.12-2.00)$ \\
\hline Mosaicity $\left[{ }^{\circ}\right]$ & 0.066 \\
\hline $\mathrm{R}_{\text {r.i.m. }}$ & $0.081(0.578)$ \\
\hline Completeness $(\%)$ & $99.4(98.4)$ \\
\hline No.of observed reflections & $363224(57821)$ \\
\hline No. of unique reflections & $89792(14286)$ \\
\hline Mean I/ $\sigma(\mathrm{I})$ & $13.9(2.6)$ \\
\hline Overall B-factor from Wilson plot $\left(\AA^{2}\right)$ & 27.1 \\
\hline Optical resolution $[\AA]$ & 1.60 \\
\hline \multicolumn{2}{|c|}{ Structure Refinement } \\
\hline Resolution $[\AA]$ & $30.0-2.0$ \\
\hline No. of reflections, working set & $88855(6133)$ \\
\hline No. of reflections, test set & $898(69)$ \\
\hline $\mathrm{R}_{\text {cryst }}$ & 0.152 \\
\hline $\mathrm{R}_{\text {free }}$ & 0.196 \\
\hline DPI $[\AA]$ & 0.1407 \\
\hline No. of protein atom & 10581 \\
\hline No. of ions & 11 \\
\hline No. of atoms (IPM) & 48 \\
\hline (NADH) & 176 \\
\hline (other organic) & 225 \\
\hline No. of water molecules & 440 \\
\hline R.m.s. deviations bonds $(\AA)$ & 0.02 \\
\hline angles $\left({ }^{\circ}\right)$ & 1.99 \\
\hline Average B-factors protein $(\AA 2)$ & 17.0 \\
\hline ions & 29.3 \\
\hline IPM & 29.9 \\
\hline NADH & 23.5 \\
\hline other organic & 45.7 \\
\hline water molecules & 35.2 \\
\hline Ramachandran plot, most favoured (\%) & 96.3 \\
\hline allowed (\%) & 3.7 \\
\hline
\end{tabular}


Table 2. Atomic interactions in the active site of $T t$-IPMDH-Mn ${ }^{2+}-$ IPM-NADH structure The atomic distances were derived from the crystallographic coordinates (pdb: 4F7I). H-bonds and electrostatic interactions are considered with the distance limits of 3.5 and $4.5 \AA$-s, respectively.

\begin{tabular}{|c|c|c|}
\hline Atom 1 & Atom 2 & Distance $(\AA)$ \\
\hline \multirow[t]{2}{*}{ Arg94:NH1 } & IPM:O4 & 2.64 \\
\hline & w2015:O & 3.04 \\
\hline \multirow[t]{4}{*}{ Arg94:NH2 } & Glu270:OE1 & 4.47 \\
\hline & Glu270:OE2 & 2.89 \\
\hline & IPM:O3 & 2.65 \\
\hline & IPM:O4 & 3.49 \\
\hline \multirow[t]{2}{*}{ Arg104:NH1 } & Asp241:OD1 & 4.10 \\
\hline & IPM:O2 & 3.22 \\
\hline \multirow[t]{5}{*}{ Arg104:NH2 } & Glu270:OE2 & 4.44 \\
\hline & IPM:O2 & 3.11 \\
\hline & IPM:O3 & 3.54 \\
\hline & w2010:O & 2.68 \\
\hline & w2022:O & 3.10 \\
\hline \multirow[t]{2}{*}{ Arg132:NH1 } & IPM:O2 & 4.10 \\
\hline & IPM:O4 & 3.27 \\
\hline \multirow[t]{4}{*}{ Arg132:NH2 } & Tyr139:OH & 3.16 \\
\hline & Asp241:OD1 & 4.45 \\
\hline & IPM:O4 & 2.65 \\
\hline & IPM:O5 & 3.59 \\
\hline \multirow[t]{3}{*}{ Tyr139:OH } & Asp241:OD2 & 3.64 \\
\hline & Lys185':NZ & 3.71 \\
\hline & IPM:O5 & 2.66 \\
\hline \multirow[t]{7}{*}{ Lys185':NZ } & IPM:O1 & 3.07 \\
\hline & IPM:O5 & 2.85 \\
\hline & Asp241:OD1 & 3.30 \\
\hline & Asp241:OD2 & 2.62 \\
\hline & Asp217’:OD1 & 3.78 \\
\hline & Asp217’:OD2 & 3.60 \\
\hline & w2013:O & 2.88 \\
\hline \multirow[t]{2}{*}{ Asn187'ND2 } & NADH:O2D & 2.85 \\
\hline & w2013:O & 2.85 \\
\hline Asp217’’OD1 & w2004:O & 2.89 \\
\hline \multirow[t]{5}{*}{ Asp217':OD2 } & IPM:O1 & 3.20 \\
\hline & w2001:O & 3.41 \\
\hline & w2002:O & 2.95 \\
\hline & w2004:O & 3.13 \\
\hline & w2013:O & 3.58 \\
\hline \multirow[t]{4}{*}{ Asp241:OD1 } & IPM:O1 & 3.01 \\
\hline & IPM:O2 & 3.18 \\
\hline & w2001:O & 2.97 \\
\hline & w2006:O & 3.44 \\
\hline \multirow[t]{2}{*}{ Asp245:OD1 } & w2001:O & 2.76 \\
\hline & w2002:O & 3.10 \\
\hline Asp245:OD2 & w2006:O & 2.60 \\
\hline Glu270:OE1 & NADH:N7N & 2.78 \\
\hline \multirow[t]{2}{*}{ Glu270:OE2 } & w2010:O & 2.80 \\
\hline & w2012:O & 2.86 \\
\hline
\end{tabular}




\begin{tabular}{lll}
\hline $\mathrm{K}^{+}$ & Gly70:O & 2.59 \\
& Ser71:OG & 2.89 \\
& Pro271:O & 2.58 \\
& His273:O & 2.86 \\
& Glu270:OE1 & 2.67 \\
& NADH:N7N & 2.71 \\
\hline $\mathrm{Mn}^{2+}$ & Asp217':OD2 & 2.05 \\
& Asp241:OD1 & 2.11 \\
& IPM:O1 & 2.09 \\
& IPM:O2 & 2.42 \\
& w2001:O & 2.25 \\
& w2002:O & 2.16 \\
\hline w2013:O & IPM:O1 & 3.06 \\
w2013:O & w2004:O & 2.82 \\
w2002:O & IPM:O2 & 3.10 \\
w2022:O & IPM:O2 & 3.29 \\
& IPM:O3 & 2.63 \\
w2004:O & NADH:N7N & 2.86 \\
w2023:O & NADH:O1N & 2.68 \\
w2006:O & NADH:O1N & 2.63 \\
& w2002:O & 2.74 \\
\hline IPM:O2 & w2004:O & 2.89 \\
\hline
\end{tabular}


Table 3. Calculated relative energies (in $\mathbf{k c a l} / \mathbf{m o l}$ at the B3LYP/6-311++G**/MM level): C1-C2-C3-C5 dihedral angle (D, in degrees) of IPM, and the intramolecular $\mathrm{C} 4 \mathrm{~N}\left(\mathrm{NAD}^{\dagger}\right)$ - $\mathrm{C} 2(\mathrm{IPM})$ distance (in $\AA$ ) of reactants (R), transition states (TS1 and TS2), intermediates (I) and products (P) along the reaction profiles. The geometrical parameters were obtained at the B3LYP/6-31G*/MM level. The value of TS2* shows the activation energy of the hydride transfer reaction with respect to the intermediate.

The three different profiles represent results with three parallel calculations applying the QM2 region in each case, as given in the Experimental Section.

The reference values of the $\mathrm{C} 4 \mathrm{~N}\left(\mathrm{NAD}^{+}\right)-\mathrm{C} 2(\mathrm{IPM})$ distance measured in the X-ray structure for the two subunits is $3.01 \AA$ (chain $\mathrm{A}$ ) and $3.02 \AA$ (chain $\mathrm{B}$ ), and those of the $\mathrm{C} 1-\mathrm{C} 2-\mathrm{C} 3-\mathrm{C} 5$ dihedral angles are $-149^{\circ}$ (chain A) and $-142^{\circ}$ (chain B), respectively.

\begin{tabular}{|c|c|c|c|c|c|c|c|c|c|c|c|c|c|c|c|c|c|c|}
\hline & \multicolumn{9}{|c|}{$\mathrm{Mn}^{2+}$} & \multicolumn{9}{|c|}{$\mathrm{Mg}^{2+}$} \\
\hline & \multicolumn{3}{|c|}{ Profile 1} & \multicolumn{3}{|c|}{ Profile 2} & \multicolumn{3}{|c|}{ Profile 3} & \multicolumn{3}{|c|}{ Profile 1} & \multicolumn{3}{|c|}{ Profile 2} & \multicolumn{3}{|c|}{ Profile 3} \\
\hline & $\Delta \mathrm{E}$ & $\mathrm{D}$ & $\begin{array}{c}\mathrm{C} 4 \mathrm{~N}- \\
\mathrm{C} 2\end{array}$ & $\Delta \mathrm{E}$ & $\mathrm{D}$ & $\begin{array}{c}\mathrm{C} 4 \mathrm{~N}- \\
\mathrm{C} 2\end{array}$ & $\Delta \mathrm{E}$ & $\mathrm{D}$ & $\begin{array}{c}\text { C4N- } \\
\text { C2 }\end{array}$ & $\Delta \mathrm{E}$ & $\mathrm{D}$ & $\begin{array}{c}\mathrm{C} 4 \mathrm{~N}- \\
\mathrm{C} 2\end{array}$ & $\Delta \mathrm{E}$ & $\mathrm{D}$ & $\begin{array}{c}\mathrm{C} 4 \mathrm{~N}- \\
\mathrm{C} 2\end{array}$ & $\Delta \mathrm{E}$ & $\mathrm{D}$ & $\begin{array}{c}\mathrm{C} 4 \mathrm{~N}- \\
\mathrm{C} 2\end{array}$ \\
\hline $\mathrm{R}$ & 0.0 & -173.1 & 3.059 & 0.0 & -177.4 & 3.014 & 0.0 & -175.4 & 2.997 & 0.0 & -172.2 & 3.060 & 0.0 & -176.7 & 3.030 & 0.0 & -174.2 & 3.006 \\
\hline TS1 & 4.5 & -171.6 & 3.038 & 2.7 & -176.9 & 2.989 & 3.1 & -174.2 & 2.974 & 4.1 & -171.4 & 3.040 & 3.0 & -176.0 & 2.997 & 3.2 & -173.0 & 2.977 \\
\hline I & -3.4 & -171.7 & 2.993 & -1.9 & -176.4 & 2.947 & -7.5 & -172.5 & 2.959 & -2.4 & -171.3 & 3.009 & -0.5 & -175.4 & 2.961 & -6.6 & -171.7 & 2.971 \\
\hline TS2 & 11.6 & -168.4 & 2.654 & 14.7 & -174.6 & 2.599 & 10.8 & -168.6 & 2.629 & 12.1 & -162.5 & 3.029 & 15.1 & -172.7 & 2.641 & 9.9 & -170.4 & 2.579 \\
\hline $\mathrm{P}$ & 5.9 & -159.5 & 2.983 & 11.1 & -166.0 & 2.870 & 7.8 & -162.3 & 2.867 & 6.4 & -159.1 & 3.092 & 12.0 & -166.2 & 2.860 & 5.9 & -161.1 & 2.901 \\
\hline $\mathrm{TS} 2 *$ & 15.0 & & & 16.6 & & & 18.3 & & & 14.5 & & & 15.6 & & & 16.5 & & \\
\hline
\end{tabular}




\section{Scheme Legends}

Scheme 1 General catalytic mechanism of oxidative decarboxylases. R represents an alkyl-group and E symbolizes the enzyme.

Scheme 2 Proposed reaction mechanism of IPMDH. iPr represents the isopropyl-group. Step 1 and Step 2 represent deprotonation and hydride transfer, respectively. 
Scheme 1

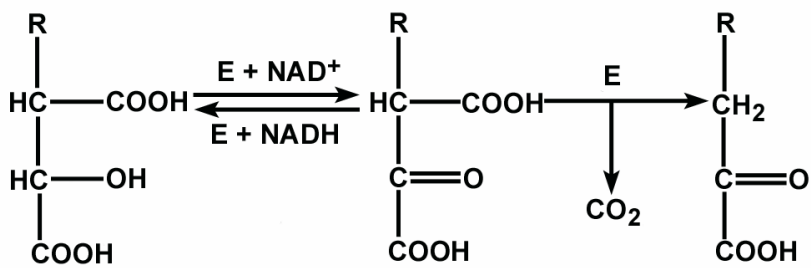

Scheme 2
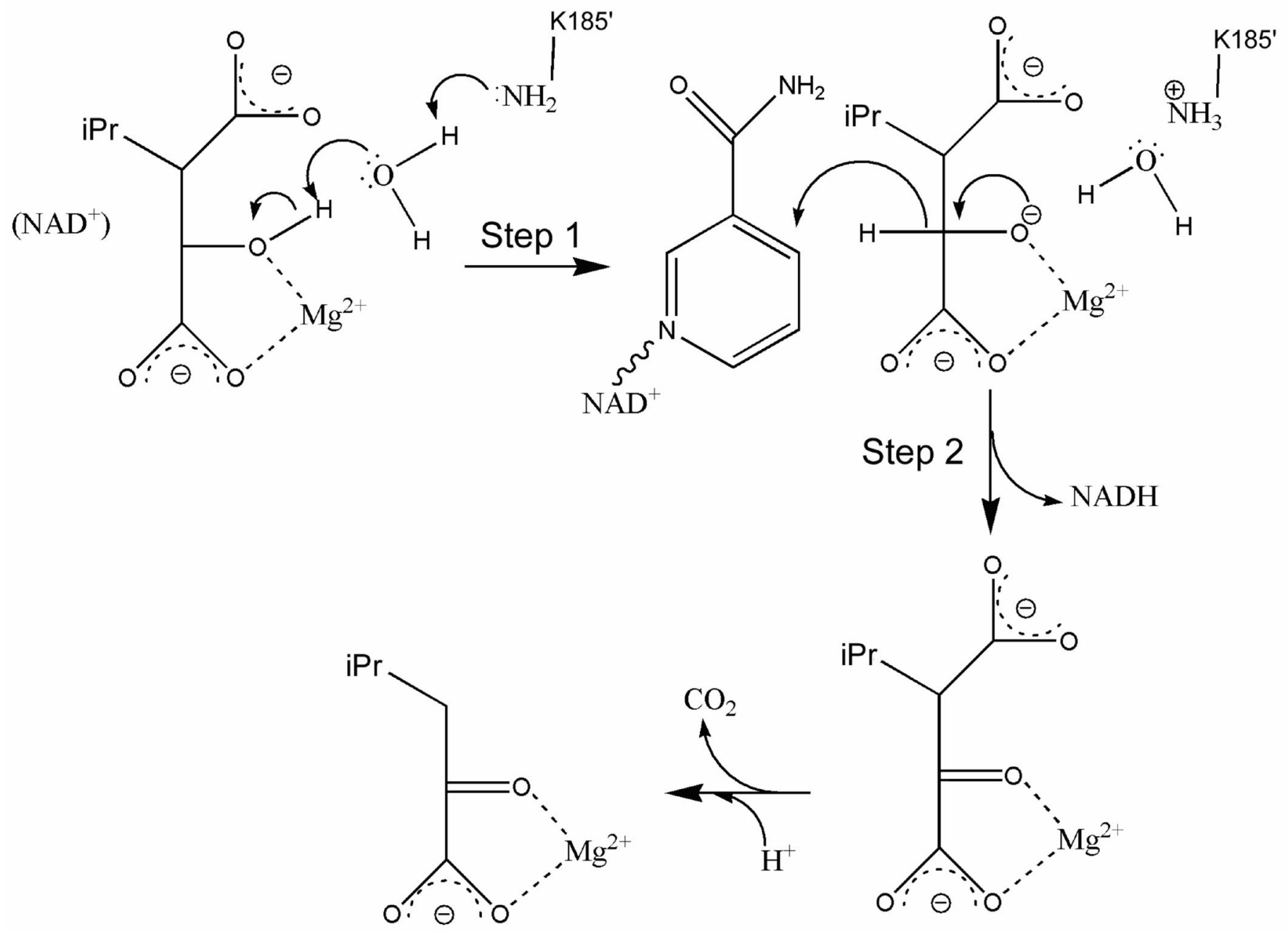


\section{Figure Legends}

Figure 1. Crystal structure (ribbon diagram) of IPMDH in complex with NADH, IPM and $\mathrm{Mn}^{2+}$. (A) IPMDH dimer with one subunit coloured in red and the other in grey. (B) IPMDH monomer with the two structural domains coloured in red and cyan, respectively. The positions of MnIPM and NADH in the structure are identified by black and grey ball-and-sticks, respectively.

Figure 2. Comparison of the protein chain conformations of $T t$-IPMDH in the various crystal structures The $\mathrm{C} \alpha$ traces of the present structure of $T t$-IPMDH- $\mathrm{Mn}^{2+}-\mathrm{IPM}-\mathrm{NADH}$ (red), the previously determined $T t$-IPMDH-Mn ${ }^{2+}$-IPM (green), $T t$-IPMDH- $\mathrm{Mn}^{2+}$-NADH (blue) and apo-Tt-IPMDH (black) structures are superimposed according to the inner $\beta$-strands of domain 1 (A) and domain 2 (B), respectively

Fig. 3 Omit difference electron density map (contoured at the $1.0 \sigma$ level) of the ligands bound to the quaternary $T t$-IPMDH-Mn ${ }^{2+}-$ IPM-NADH. The electron density clearly shows that the nicotinamide ring of the NADH is planar as it would be expected for the co-factor substrate $\mathrm{NAD}^{+}$. The distance between $\mathrm{C} 2$ atom of IPM and the $\mathrm{C} 4 \mathrm{~N}$ atom of the bound $\mathrm{NADH}$ is indicated.

Figure 4. Illustration of binding of IPM, $\mathrm{Mn}^{2+}$ and NADH in the active site cavity of Tt-IPMDH monomer (surface-covered model) located between its two domains. The stick models of the substrates are coloured according to their atoms; $\mathrm{Mn}^{2+}$ is coloured as purple. This and the above structural figures have been prepared by the aid of software Insight II 95.0 (Biosym/MSI, San Diego, CA, USA).

Figure 5. Binding details of IPM, $\mathrm{Mn}^{2+}$, NADH and $\mathrm{K}^{+}$at the level of side-chain interactions. (A) and (B) are overlapping, but illustrate different aspects of the active site interactions. Locations of the ligands, $\mathrm{Mn}^{2+}$ and $\mathrm{K}^{+}$in the active site of $T t$-IPMDH-Mn ${ }^{2+}$-IPM-NADH complex are represented schematically. The interacting side-chains from the two different subunits are coloured black and green, respectively. IPM and $\mathrm{NAD}^{+}$are coloured red, while the metals ion is coloured purple and the water molecules are coloured blue. The side chains are illustrated irrespective of their protonation state. The most important atomic contacts $(\mathrm{H}-$ bonds and electrostatic interactions with the distance limits of 3.5 and $4.5 \AA$-s, respectively) are shown by the dashed lines. More complete list of the contacts are summarised in Table 2. The two bound cations are about $9 \AA$ distant from each other. For clarity, the numerous hydrophobic contacts of the carbonic atoms are not illustrated. The figure was prepared by using MDL ISIS Draw 2.5.

Fig. 6 The conformation of IPM molecules bound in the quaternary (A) and the ternary (B) complexes, respectively. The $\mathrm{C} 1-\mathrm{C} 2-\mathrm{C} 3-\mathrm{C} 5$ dihedral angles of the IPM molecules bound to the quaternary and the ternary complexes, respectively, are indicated. The substrates are colored according to atoms. 
Figure 7. Two-dimensional potential energy surface of the hydride and proton transfer reactions of the $\mathbf{M g}^{2+}$ containing system. TS1 and TS2 refer to the transition states of proton transfer and hydride transfer, respectively. The abbreviations $\mathrm{R}$, I and $\mathrm{P}$ stand for the reactant, intermediate and the product.

Figure 8. Schematic representation of the critical points along the reaction profiles of the IPMDHcatalyzed reaction. (A) reactant state; (B) transition state for proton transfer (TS1) from the hydroxyl group of IPM to Lys185' via a water molecule (w) that corresponds to w2013 in the X-ray structure; (C) intermediate; (D) transition state of hydride transfer (TS2) to $\mathrm{NAD}^{+},(\mathrm{E})$ product state; (F) reaction energy diagram, where the energy values on the profiles match those for profiles 1, 2, and 3 for the IMPDH-IPM$\mathrm{NAD}^{+}-\mathrm{Mg}^{2+}$ complex shown in Table $3 . \mathrm{H}_{\mathrm{p}}$ and $\mathrm{H}_{\mathrm{w}}$ denote the protons originally belonging to the $\mathrm{OH}$-group of IPM and the catalytic water molecule, respectively. $\mathrm{H}_{\mathrm{h}}$ denotes the hydride-ion to be transferred. 
Fig. 1
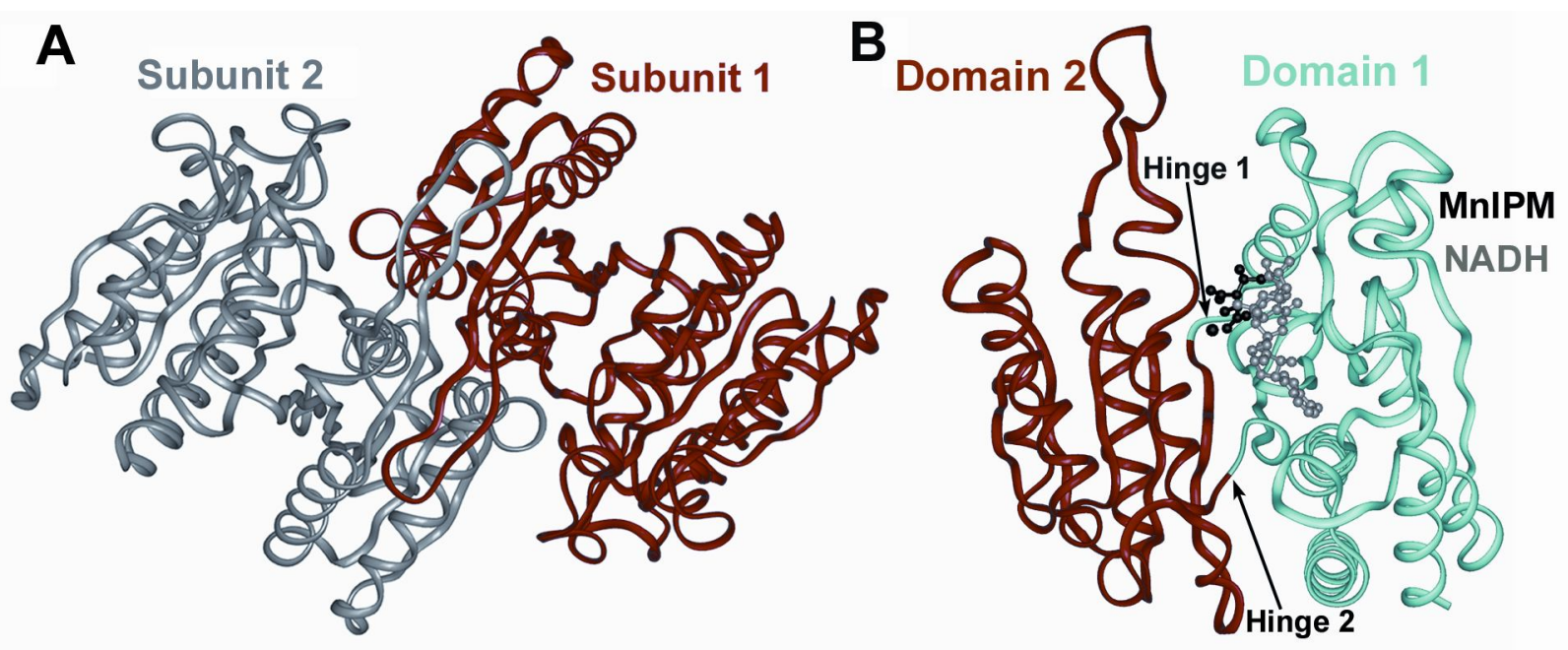

Fig. 2

A

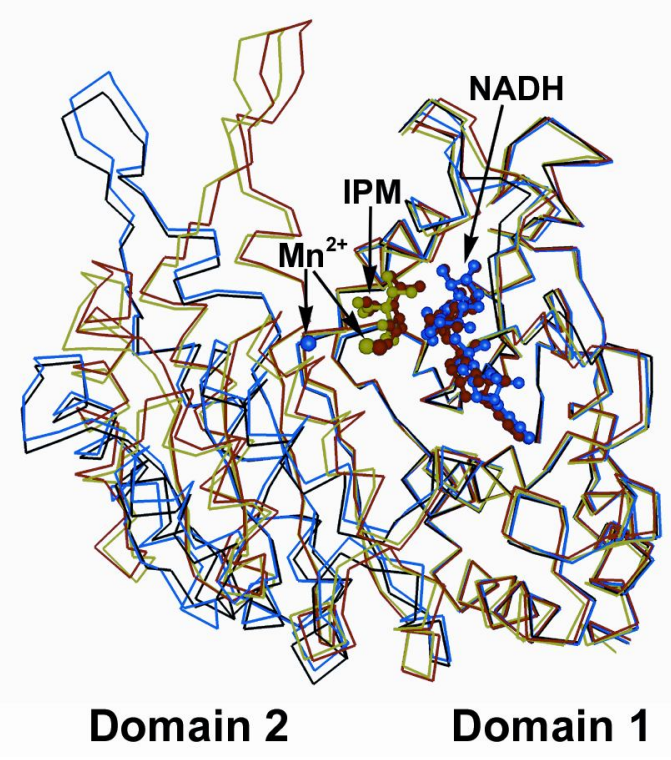

B

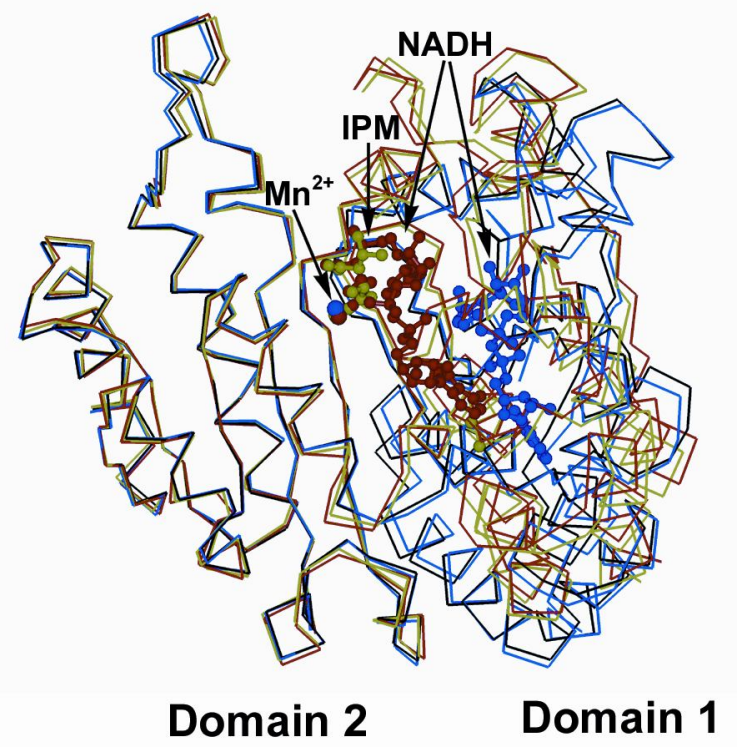


Fig. 3
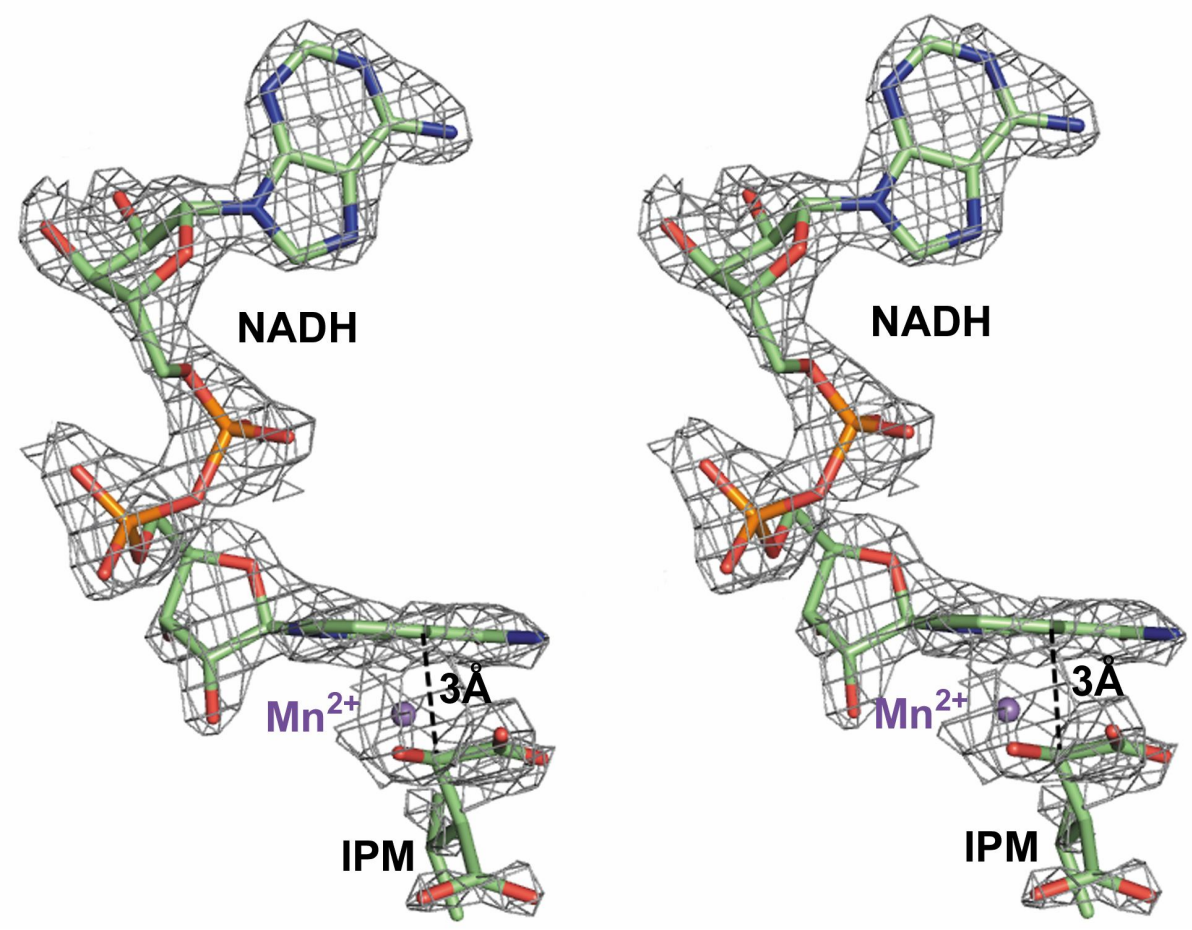

Fig. 4

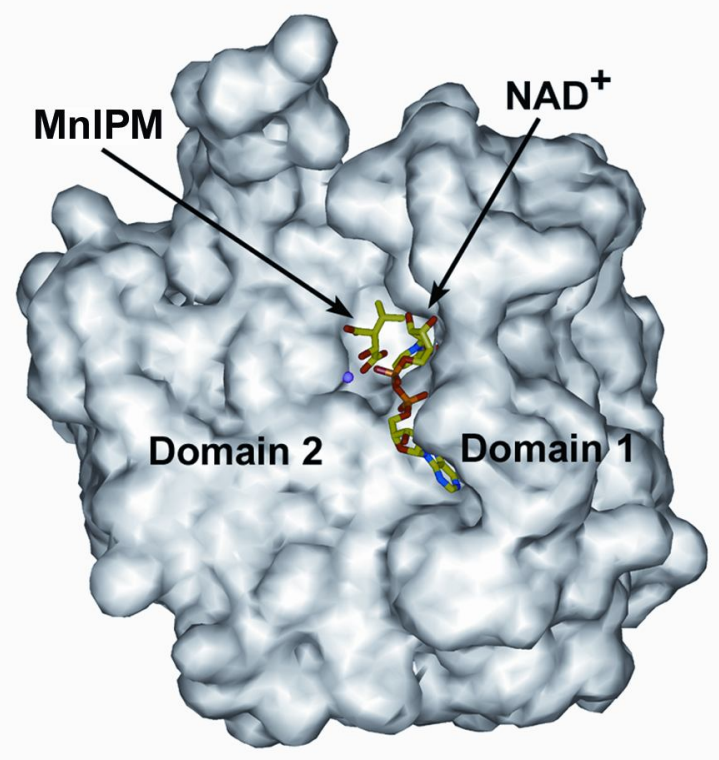


Fig. 5

A

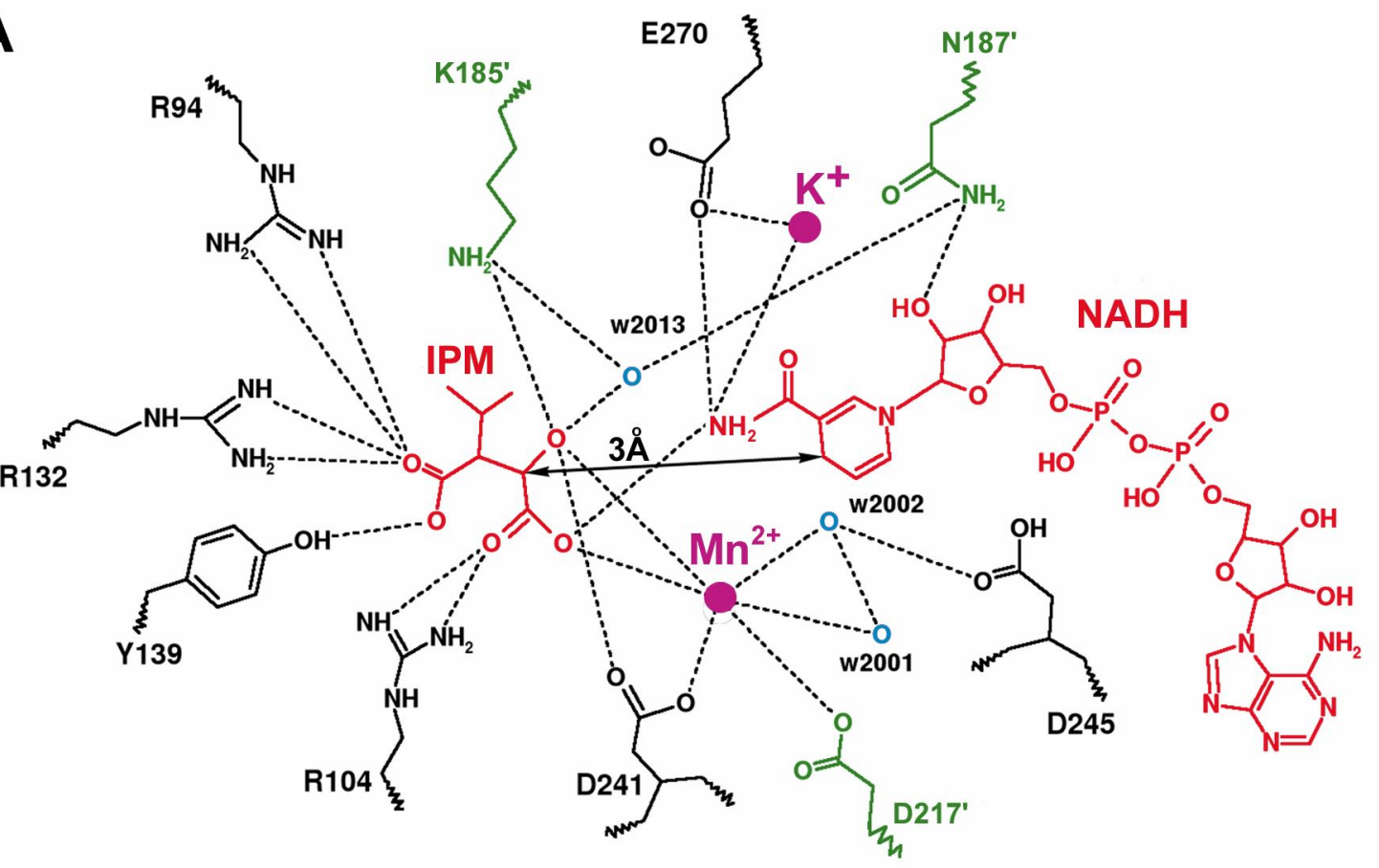

B

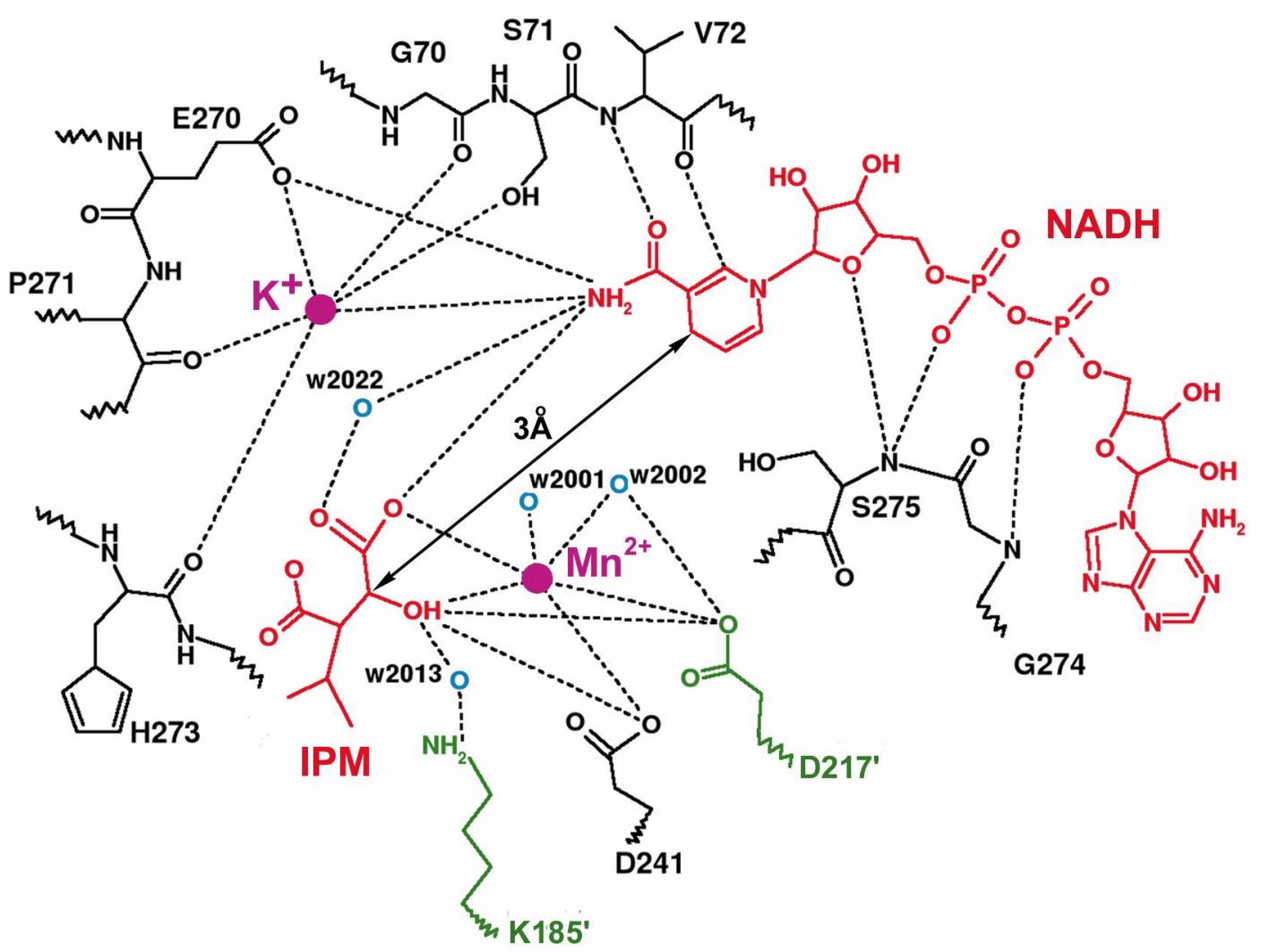


Fig. 6
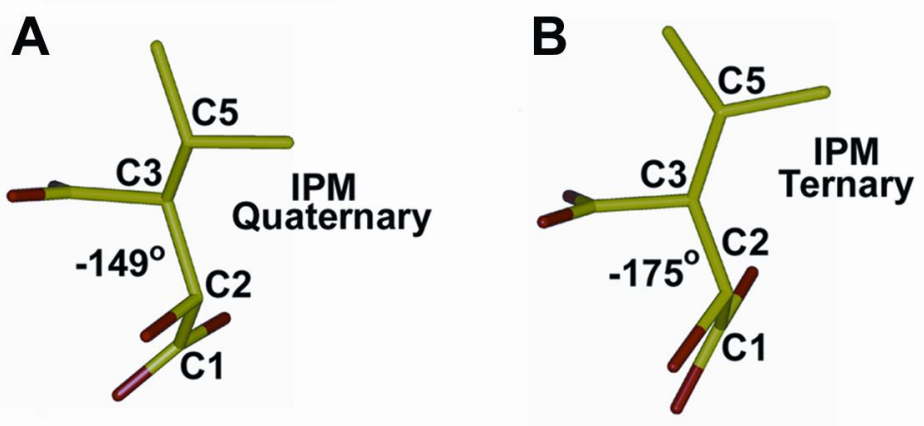

Fig. 7

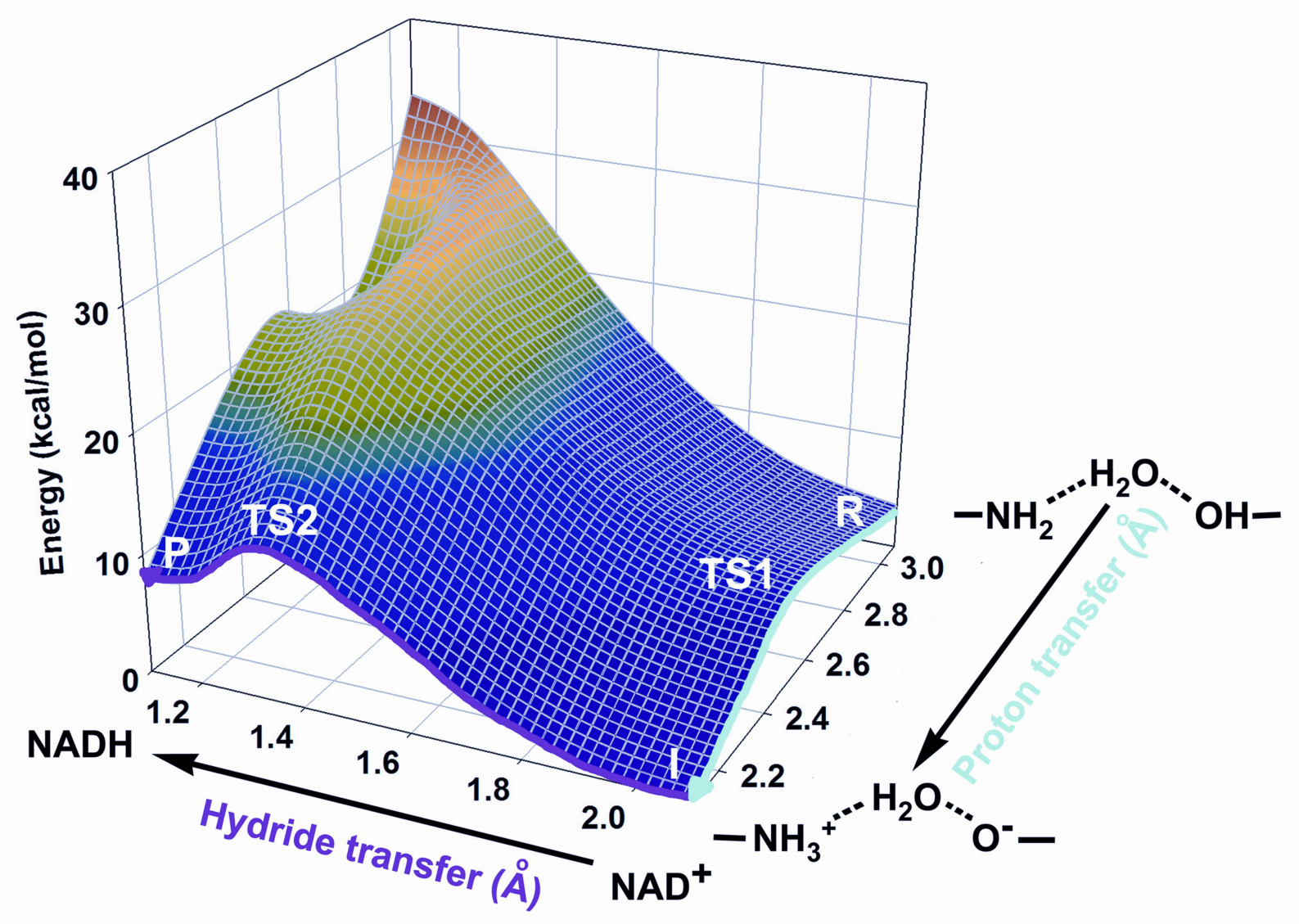


Fig. 8
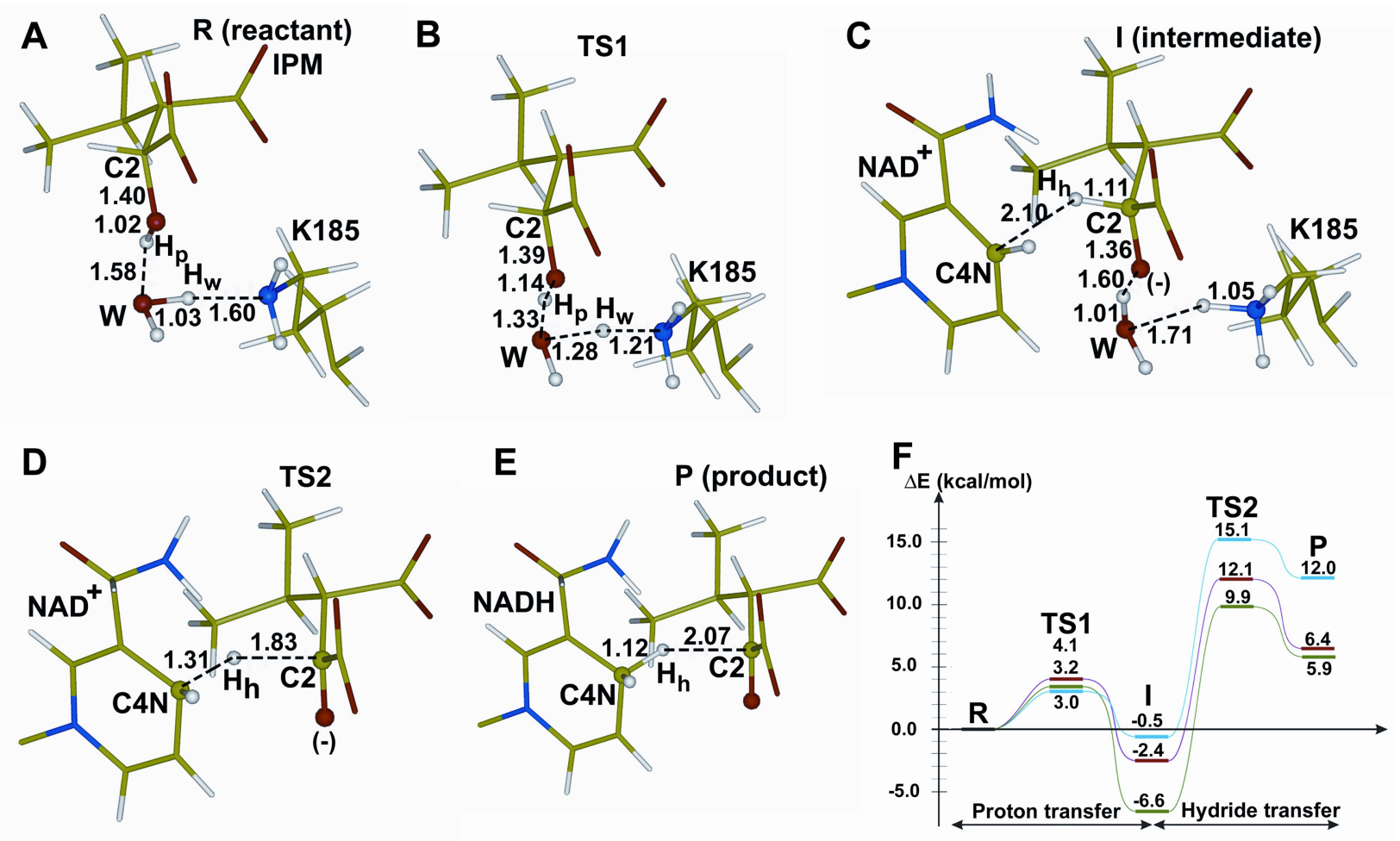